NBER WORKING PAPER SERIES

\title{
NETWORKS OR NEIGHBORHOODS? CORRELATIONS IN THE USE OF PUBLICLY-FUNDED MATERNITY CARE IN CALIFORNIA
}

\author{
Anna Aizer \\ Janet Currie \\ Working Paper 9209 \\ http://www.nber.org/papers/w9209
NATIONAL BUREAU OF ECONOMIC RESEARCH
1050 Massachusetts Avenue
Cambridge, MA 02138
September 2002

Orley Ashenfelter, Guido Imbens, Erzo Luttmer, Enrico Moretti and seminar participants at UC Berkeley, UCLA, Cal State Fullerton, ITAM, Princeton, and the Harris School provided helpful comments. Aizer thanks the Social Science Research Council for support. Currie thanks NIH for support and the California Dept. of Health for access to the data. None of these individuals or agencies are responsible for the contents of this paper. The views expressed herein are those of the authors and not necessarily those of the National Bureau of Economic Research.

(C) 2002 by Anna Aizer and Janet Currie. All rights reserved. Short sections of text, not to exceed two paragraphs, may be quoted without explicit permission provided that full credit, including (C) notice, is given to the source. 
Networks or Neighborhoods? Correlations in the Use of Publicly-Funded Maternity

Care in California

Anna Aizer and Janet Currie

NBER Working Paper No. 9209

September 2002

JEL No. I18, I38

\begin{abstract}
$\underline{\text { ABSTRACT }}$
This study focuses on "network effects" in the utilization of publicly funded prenatal care using Vital Statistics data from California for 1989 to 2000. Networks are defined using 5-digit zipcodes and a woman's racial or ethnic group. Like others, we find evidence that the use of public programs is highly correlated within groups defined using race/ethnicity and neighborhoods. These correlations persist even when we control for many unobserved characteristics by including zipcode-year fixed effects, and when we focus on the interaction between own group behavior and measures of the potential for contacts with other members of the group ("contact availability"). However, the richness of our data allows us to go further and to conduct several tests of one hypothesis about networks: That the estimated effects represent information sharing within groups. The results cast doubt on the idea that the observed correlations can be interpreted as evidence of information sharing, and point instead to differences in the behavior of the institutions serving different groups of low-income women as the primary explanation for group-level differences in the take-up of this important public program.
\end{abstract}

\author{
Anna Aizer \\ Bendheim-Thoman Center for \\ Research on Child Well-Being \\ Princeton University \\ Princeton NJ, 08544 \\ aaizer@princeton.edu
}

Janet Currie

Dept. of Economics, UCLA

405 Hilgard Ave.

Los Angeles CA

90095-1477

currie@simba.sscnet.ucla.edu 


\section{Introduction}

Social scientists have long been interested in the interpretation of what have come to be known as neighborhood and network effects. Moffitt ( forthcoming) provides a survey of much of this literature. Prominent recent examples include Katz, Kling and Liebman (2001) and Ludwig, Duncan, and Hirschfield (2001), who provide evidence from a randomized experiment that moving to a better neighborhood can increase health and well-being and reduce ones exposure to crime; Duflo and Saez (2001) who also conduct an experiment and show that providing information about retirement programs to some members of a group has small effects on the behavior of other members of the group; Borjas $(1992,1995)$ who shows that the outcomes of children are associated with the mean levels of "ethnic capital" among adults in their communities, even after controlling for the human capital of their own parents; Borjas and Hilton (1996) who show that there are strong ethnic correlations in the types of welfare programs used by different immigrant groups; and Bertrand, Luttmer and Mullainathan (2000), who show that a women's propensity to use welfare increases with the number of coethnics in the area if those coethnics have a high propensity to use welfare nationally.

However, in the absence of a well-designed experiment, it is difficult to determine whether correlations in observed behaviors within groups represent a causal influence of one person on another from the same group (for example, through the sharing of information) or some unmeasured characteristic of the group or neighborhood. In this paper, we attempt to shed light on this issue using a very rich source of data about the use of publicly funded maternity care in California.

Over the past 20 years, federal and state governments have invested considerable resources in efforts to get women into timely prenatal care. In California, expansions of Medicaid income cutoffs and state-funded programs have extended eligibility for public prenatal and delivery services to women in families with incomes up to 300 percent of the federal poverty line. However, large differences in the utilization of prenatal care persist between racial and ethnic groups and across geographic areas. Understanding the reasons for these differences is key if they are to be successfully reduced. In particular, it is important to know whether they reflect neighborhood 
characteristics such as differential access to facilities or differences in the knowledge or attitudes about public programs that might be shared by women in different social networks. If networks are important, then this has implications for the optimal design of outreach programs aimed at getting women into prenatal care. More generally, our results may shed some light on the widespread problem of non-participation by people eligible for social programs and on the nature of the estimated network effects.

This study focuses on racial, ethnic, and spacial variation in the utilization of publicly funded prenatal care using Vital Statistics data from California's Birth Public Use files from 1989 to 2000. We define "networks" using a pregnant woman's 5-digit zipcode and other new mothers in the same racial or ethnic group. Thus, our implicit assumption about networks is that pregnant women are most likely to be influenced by new mothers from the same area and ethnic group in terms of their own choices about takeup of public maternity care programs. While it is reasonable to assume that pregnant women seek the advice of new mothers, it may be more problematic to assume that they interact primarily with women from their own racial or ethnic group. However, as we will see below, the index woman's behavior is much more highly correlated with that of women from the same racial or ethnic group than it is with the behavior of women from other groups which provides some support for defining networks along these lines.

The richness of our data allows us to control for possibly omitted variables to a greater degree than many other non-experimental studies. In particular, we can include zipcode-year effects in many of our models in order to control for characteristics of local neighborhoods. We explore various measures of "network effects" including those suggested by Bertrand, Luttmer, and Mullainathan (2000). Specifically, in these regressions we interact the fraction of local coethnics who used the public program in the last 11 months with a measure of the "density" of the local network and treat the interaction as a measure of the importance of networks. The intuition is that if networks represent contacts between individuals within groups, then the effect of networks should be greater where contacts are more likely. Our results are consistent with theirs in that we find 
strong evidence of an interactive effect.

However, the more important contribution of our study is that we attempt to say something about the nature of this effect. A leading hypothesis about networks is that people rely on them for information about public programs. We test this hypothesis by comparing estimated network effects for first and second births. Once a woman has had a publicly-funded delivery, she learns both about the existence of the public program (if she did not know already), and that she is eligible. Hence, estimated network effects ought to be lower for second births than for first births if this type of information sharing is important. However, we find that the estimated network effects are similar for first and second births, suggesting that estimated effects do not reflect this type of information sharing.

In a second investigation, we estimate models that include fixed effects for the hospital of delivery interacted with the year of delivery, and find that the estimated effects of networks are either greatly reduced or eliminated. Note that the zipcode-year effects included in our models absorb measures of the local availability of care. The fact that the inclusion of hospital-year fixed effects has such a dramatic effect indicates that women in different ethnic groups use different hospitals regardless of where they live, and that this fact drives the estimated correlations in the use of public maternity care services. This strong sorting of women across hospitals may be facilitated by networks, but it is also likely to indicate differential behavior by hospitals. For example, Duggan (2000) provides compelling evidence that many California hospitals changed the extent to which they provided publicly funded delivery services over the first half of our sample period. Moreover, if hospitals did not differ in terms of the way that they treated different groups of women, then there would be no information relevant to hospital choice for a network to share.

Finally, we compare estimated network effects for foreign-born and native-born Hispanic women. We hypothesize that the information requirements of foreign-born women are greater than those of native-born women because of the uncertainty that surrounds their eligibility for public prenatal care programs and the possible effects that use of such programs could have on their 
immigration status, and perhaps because of language barriers. However, our estimates of network effects in the use of publicly funded prenatal care are quite similar for native and foreign born Hispanic women, and independent of whether we define the "network" as including all Hispanic women or only native/foreign born women. This result suggests once again that informationsharing within networks is not the primary reason for the observed correlations in use of publicly funded programs.

To summarize, like many others, we find evidence that behavior is highly correlated within groups defined using race/ethnicity and neighborhoods. These correlations persist even when we control for many unobserved characteristics via zipcode-year effects, and when we focus on the interactive effect of own group behavior and own group "contact availability". However, our investigations cast doubt on the idea that these correlations can be interpreted as evidence of information sharing, and point instead to differences in the behavior of the institutions serving different groups of low-income women as the primary explanation for the estimated group-level correlations in takeup.

The rest of this paper proceeds as follows. First, we provide some background about the importance of prenatal care and efforts to promote prenatal care both nationally and in California. Second, we describe our methods and the California Birth Public Use file that we use in our analyses, and provide a description of some of the continuing disparities in the use of prenatal care between groups and areas. We describe our results in section 3 and conclusions appear in section 4.

\section{Background}

a) Provision of Publicly Funded-Prenatal and Delivery Care in California

The Medicaid program pays for the prenatal care and deliveries of low income mothers. Medicaid is a joint federal-state matching grant program which means that the federal government matches state payments as long as the state program remains within certain guidelines. Since April 
1990, these guidelines have specified that Medicaid cover maternity care for women in households with incomes less than or equal to $133 \%$ of the federal poverty line. This law had the effect of greatly expanding eligibility for Medicaid coverage of maternity care in many states (c.f. Currie and Gruber, 1996a,b).

California opted to use state-only funds to extend Medicaid coverage to women up to $185 \%$ of poverty starting in 1988 , and up to $200 \%$ of poverty starting in April 1990 . In addition, the California Access for Infants and Mothers Program (AIM), begun in February 1992, pays for maternity care for women with incomes between 200 and 300\% of poverty. ${ }^{1}$ In 1997, there were 524,174 births in California. Of these, 270,325 were paid for by private insurers, 222,425 were paid for by Medi-Cal, 19,518 were "unsponsored" births, and 3,075 were paid for by AIM. Thus, public insurance covered a surprising $43 \%$ of all births, and only $3.7 \%$ of births were unsponsored.

As we will show below, the fraction of women receiving publicly-funded prenatal care and commencing care in the first trimester has consistently been smaller than the fraction of women getting public coverage of their deliveries, especially among Hispanic women. In an effort to increase utilization of timely prenatal care, California has conducted significant outreach efforts to pregnant women under its BabyCal program since 1991.

\section{b) Non-Monetary Barriers to Care}

The fact that many people eligible for social programs do not participate in them suggests that lack of income eligibility is not the only barrier to care. For example, Blank and Ruggles (1996) find that only two-thirds of those eligible for AFDC and Food Stamps participate. Blank and

1. Women must also be less than 31 weeks pregnant, uninsured, and ineligible for Medi-Cal or Medicare payments. Unlike Medicaid, AIM is not an entitlement, so that when funding for the program runs out, eligible women cannot be served. For example, in February 1994, enrollment was suspended for the remainder of the budget year, and eligibility was temporarily reduced to women with incomes less than $250 \%$ of poverty. In 1998, the budget for the program was $\$ 41,000,000$ and it covered roughly 4,000 births for a cost per birth of $\$ 10,250$. If it were assumed that AIM births would otherwise have been unsponsored, then AIM would have reduced unsponsored births by 13.6\%. See Nario (1998) for more information. 
Card (1991) find similar results for participation in the Unemployment Insurance program. Currie and Gruber (1996a,b) find comparable rates of non-participation among women and children eligible for Medicaid.

Surveys of eligible non-participants in means-tested programs find that welfare stigma (c.f. Moffitt, 1983) is often mentioned, but that it is seldom the only barrier to participation. Lack of information about ones own eligibility and about the magnitude of the benefits available is a common problem. For example, Daponte, Sanders, and Taylor (1999) found that informing households about their eligibility, as well as about the size of the benefit available to them, increased participation in the Food Stamp program. Aizer (2001) shows that enrollments in the State Children's Health Insurance Program (SCHIP) are higher in states that contract out outreach efforts, suggesting that effective outreach can increase take up. This literature suggests that it is possible that lack of take up of public prenatal care programs in California reflects simple ignorance about the existence of the programs despite the existence of the BabyCal campaign.

Direct transactions costs associated with enrolling in Medicaid are another serious problem. Currie and Grogger (2001) show that declines in welfare rates have significant effects on Medicaid caseloads, presumably because losing welfare eligibility means that women must go through a separate certification process to retain Medicaid benefits. Applicants for Medicaid may be required to produce birth certificates and/or citizenship papers, rent receipts and utility bills to prove residency, and pay stubs as proof of income, all within a specified number of days. And applicants are often required to return for several interviews. Up to a quarter of Medicaid applications are denied because applicants do not fulfill these administrative requirements (GAO, 1994). Aizer (2002) finds that community-based organizations that assist women in filling out applications have had a large impact on the takeup of public health insurance in California, which further underlines the importance of transactions costs.

Even women who are covered by Medicaid may have difficulty obtaining preventive care, since Medicaid typically pays about half of what private health insurance would pay. One study of 
new mothers who had arrived in emergency rooms to deliver with "no physician of record" found that 64 percent of the women cited their inability to find a doctor willing to accept them as the largest barrier to obtaining prenatal care (Aved et al., 1993). These problems may be even more severe for minority mothers. American cities are highly segregated by race and income (Massey and Denton, 1993) and urban blacks often live in parts of the city that are shunned by physicians in private practice and hence are more often served by large urban teaching hospitals (Fossett et al., 1992). New immigrants also tend to be concentrated in specific areas. These observations highlight the importance of controlling adequately for the availability of local medical facilities and resources when examining determinants of enrollment in the Medicaid program. This literature suggests that in addition to information about the existence of programs, a network might supply information about where to go for care and that this might be more important than simple information about the existence of programs.

Immigrants may face additional problems accessing publicly- funded maternity care services. In 1991, documented and undocumented aliens accounted for $45 \%$ of deliveries financed by MediCal(Norton, Kenney, and Ellwood, 1996). California's Proposition 187, which was passed in 1994, disqualified undocumented pregnant women from receiving prenatal care services. However, due to legal challenges, this law was never implemented. Moreover, health care providers flatly refused to ask women about their immigration status, citing public health concerns. In July, 1999, Governor Gray Davis officially ended the state's efforts to ban public funding of prenatal care to these women. Similarly, in 1996, the federal Personal Responsibility and Work Reconciliation Act ended federal payments for Medicaid coverage of pregnant immigrant women who entered the country after August 1996, but the state of California elected to continue coverage of these women with its own funds.

Although the 1994 and 1996 law changes limiting immigrant access to prenatal care services were never enforced in California, many observers believe that they have discouraged immigrant women from using these services (c.f. Korenbrot, forthcoming). One possibility is that anti- 
immigrant measures have heightened fears that the use of public services will lead immigrants to be considered "public charges" and thus jeopardize their right to stay in the U.S. and/or apply for citizenship. This issue was not clarified until 1999 when the Clinton administration specifically stated that use of in-kind services such as Medi-Cal would not jeopardize immigration status (Yoo and Park, 2001). These considerations suggest that a foreign-born woman seeking to use public prenatal care services would have to learn not only how to sign up and where to get care, but also about whether or not her use of the service was likely to cause immigration problems either for herself or for family members.

While it may be quite difficult for individuals to overcome these non-monetary barriers to obtaining coverage, hospitals serving large numbers of indigent women have strong incentives to help eligible women to enroll because they are required to provide care to women in active labor regardless of whether the women have the means to pay their bills. Saywell (1989) finds that uncompensated care to pregnant women was a significant financial burden for hospitals in California in the 1980s. Many hospitals have established Medicaid enrollment offices on site. If a woman in labor arrives without insurance, but appears to be Medicaid eligible, these offices will inform them of their eligibility, assist them in completing applications, and tell them how to obtain necessary documentation (GAO, 1994). Thus, births to eligible women may be covered by Medicaid even when prenatal care is not, which accounts for the fact that usage of public prenatal care services has lagged behind the public funding of deliveries (Ellwood and Kenney, 1995).

On the other hand, hospitals can certainly take steps to either encourage or discourage eligible women from presenting. Duggan (2000) discusses a change in the system of reimbursing hospitals for indigent care which made it profitable for some hospitals to increase the share of MediCal deliveries in their caseloads. Hospitals that sought to attract this clientele advertised heavily and even offered inducements such as free car seats. Hospitals that want to discourage Medi-Cal mothers can decline to establish Medicaid enrollment offices on site, fail to offer translation services, or even engage in illegal (but often unpunished) practices such as turning away patients 
(“dumping") or requiring cash payments for services. ${ }^{2}$ These strategies are likely to be particularly effective if there is another hospital nearby that is more welcoming.

\section{c) The Importance of Prenatal Care}

It is useful to study the role of network effects in the use of public prenatal care programs if only for the insight into determinants of program participation that it provides. However, given all the public effort that has been devoted to getting women to enroll in prenatal care, it is worth asking why we should care about this outcome? Many studies have shown that women who use prenatal care earlier and more faithfully have healthier babies. But this association may reflect characteristics of the mother that make her more likely to use prenatal care rather than an effect of prenatal care per se. Clinical studies have attempted to demonstrate a link between prenatal care and improved infant health. These studies generally focus on birth weight, and distinguish between two types of infants, those who are born prematurely (but may be of normal weight given their gestational age) and those who are of low weight given their gestational age. Premature babies (who are often low birth weight) account for less than seven percent of total births, but consume half of all hospital delivery charges (Marbella et al., 1998).

The results of these studies have been mixed. Prenatal care has been shown to be effective in reducing the risk of low birth weight, but only among relatively mature full-term infants. It has not been shown to reduce the risk of premature birth, or the incidence of inter-uterine growth

2. A recent report by the consumer group Public Citizen finds that these illegal practices are in fact remarkably common (Public Citizen, 2001). Of the 500 hospitals that had confirmed violations of anti-dumping laws in 1997, 1998 and 1999, only 85 had been fined as of April 2001. A less extreme tactic than dumping is to deny indigent patients certain services. A class action lawsuit was recently filed against a Los Angeles County hospital which required Medi-Cal patients in labor to pay $\$ 400$ cash on-the-spot for epidurals. State officials have termed these actions "improper" since it is illegal to charge extra fees to Medi-Cal patients. However, it does not appear that the hospital has faced any regulatory action from state or federal agencies, and in response to the scandal the state legislature found it necessary to enact a statute specifically outlawing this practice (of charging for epidurals) (Bernstein, June 17, 1999). It seems safe to assume that pregnant women who knew that they would be denied anesthesia would avoid this hospital if at all possible. 
retardation among infants who are born prematurely (Alexander and Korenbrot, 1995). Large-scale survey-based studies that have attempted to control for unobserved differences between women who do and do not seek prenatal care also typically find little or no effect of prenatal care (c.f. Rosenzweig and Schultz, 1982, 1983, 1988; Frank et al., 1991; Corman et al., 1997).

These results are puzzling given that there are good biological reasons for expecting prenatal care to be effective. Perhaps routine prenatal care is often ineffective because it does not emphasize smoking cessation, stress reduction and/or the diagnosis and treatment of mild infections (Armson and Moutquin, 1998). One study of a national sample of mothers found that many had not received advice about reducing or eliminating alcohol, smoking, and illegal drugs, eating the proper foods, and taking vitamin supplements (Kogan et al., 1994). Standard prenatal care does closely monitor maternal weight gain. Since we know that low maternal weight gain is associated with low birth weight in full term infants, this emphasis may account for the positive effect of prenatal care on birth weight among relatively mature infants that has been documented in the clinical literature. It is possible that as the results of recent research regarding the efficacy of smoking cessation programs, and the role of stress and infection in preterm delivery diffuse through the medical community, prenatal care will become a more powerful tool for improving fetal and infant health.

\section{Data and Methods}

\section{a) Data Overview}

The data for this study come from the California Birth Public Use File for 1989 to 2000. These data are abstracted from birth certificates. Variables relevant for our analysis include the mother's age, race, education, marital status, natality and 5-digit zipcode; the parity of the child; month prenatal care began; the principal source of payment for prenatal care; the principal source of payment for delivery, which may be different; and the hospital of delivery.

We distinguish three racial/ethnic groups: African-Americans (blacks), non-Hispanic whites (whites), and Hispanics. We have excluded Asians and the five percent of mothers who are of 
"other" or unknown race. Asians in California are a relatively small and very heterogeneous group. It proved impractical to use our methods to analyze subgroups of Asians due to small sample sizes. ${ }^{3}$

The outcomes we focus on are whether there was a public payor for delivery, and whether there was both a public payor for prenatal care and initiation of prenatal care in the first trimester of the pregnancy. Timeliness is an important element of prenatal care adequacy. The first visit is used to establish baselines for such things as maternal weight and blood pressure which can then be used to track the progress of the pregnancy.

We limit our analysis to mothers with less than 4 years of college. Our rationale for excluding the college educated is that most of these women are not eligible for public coverage of maternity care. Also, the vast majority of college educated women begin prenatal care in the first trimester of pregnancy so there is little variation in this outcome. We look separately at first and second births, in order to examine the way that network effects change with birth order. We found that mothers who were giving birth for the first or second time were similar, except for the fact that more first births were to single mothers (part of the explanation for this may be that many people marry after the first birth but before the second). On the other hand, higher order births were to less educated mothers on average, suggesting that a comparison of first and second births is cleaner than a comparison of first and all higher order births would be. Means for third births are shown in Appendix Table 1.

\section{b) Estimation}

As Manski (1993), Moffitt (forthcoming) and others have highlighted, correlations between

3. In an earlier version of this paper, we also attempted to estimate models for Asians. This exercise proved unsatisfactory for several reasons. First, Asians are a very heterogeneous group. However, since they are also the smallest ethnic group, it was not practical to divide them further at the zipcode level. Second, given the small numbers, many zipcodes had to be excluded from our sample because there were fewer than 25 Asian births. However, in models estimated at the MCD level, and in zipcode-level models which did not include zipcode*year fixed effects, the key interaction term was significantly positive in models for publicly funded prenatal care in the first trimester, though not for public deliveries, suggesting that in larger samples, we might obtain results similar to those reported for other groups below. 
the behavior of the index woman and other women from her "network" could reflect an endogenous effect where the propensity of an individual to behave in a particular way is causally influenced by the behavior of other members of the group; an exogenous effect where the individual's behavior is influenced by an exogenous characteristic that defines group membership; or a correlated effect where individuals from the same group tend to behave the same way because they have similar individual characteristics, or face similar constraints. Thus, it is important to control adequately for exogenous characteristics and common constraints.

One way to do this might be to control for observables thoroughly by estimating an equation of the form:

(1) $\mathrm{Y}_{\text {ait }}=\mathrm{a}_{0}+\mathrm{a}_{1} \mathrm{X}_{\text {ait }}+\mathrm{a}_{3}$ YBAROWN $_{\text {ait- } 1}+\mathrm{a}_{4} \mathrm{~N}_{\mathrm{at}}+\mathrm{a}_{5}$ YEAR $_{\mathrm{t}}+\mathrm{v}_{\mathrm{ati}}$,

where $\mathrm{Y}$ is one of the two outcomes, and the subscripts $\mathrm{i}$, a, and t denote the individual, area, and time, respectively. The vector $\mathrm{X}$ includes maternal characteristics such as education (high school dropout, high school graduate, some college); marital status; whether the mother is foreign born; and age (teen, 20-29, 30-39, 40-45, 45+). The vector $\mathrm{N}$ includes measurable time-varying characteristics of the neighborhood such as the fraction of mothers in each race/ethnic group; the fraction of births to teen mothers; the fraction of births to single mothers; and the fraction of births to mothers who are foreign born, YEAR is a vector of year dummies, and the variable YBAROWN is the fraction of women in the woman's group who used the publicly funded service in the 11 months prior to the birth month.

Model (1) can easily be augmented by defining a variable YBAROTHER, which is the fraction of other women in the zipcode who used the public service (either delivery or prenatal care) in the past 11 months, and/or by including zipcode fixed effects. In this specification, the variable YBAROTHER would help to control for time-varying characteristics of neighborhoods which affected all women, while the zipcode fixed effects would capture any variable that was relatively 
fixed over time, such as the location of hospitals.

However, even in this model, YBAROWN could capture omitted group and area specific variables, such as a new clinic that served women from a particular ethnic group rather than a network effect. Hence, following Bertrand, Luttmer, and Mullainathan (2000) we also estimate models of the form:

(2) $\mathrm{Y}_{\text {ait }}=\mathrm{a}_{0}+\mathrm{a}_{1} \mathrm{X}_{\text {ait }}+\mathrm{a}_{3}$ YBAROWN $_{\text {ait-1 }}+\mathrm{a}_{4}\left(\mathrm{YBAROWN}_{\text {ait- } 1} * \mathrm{CA}_{\text {ait }}\right)+\mathrm{a}_{5}$ YBAROTHER $_{\text {ait- } 1}+$ $\mathrm{a}_{6}$ ZIPCODE* YEAR $_{\mathrm{at}}+\mathrm{v}_{\mathrm{ati}}$,

where all the variables are defined as before and CA is "contact availability", or the fraction of new mothers in the local area who are in the index woman's group. The intuition is that even if the main effect of a variable like YBAROWN is driven by omitted variables bias, network effects ought to be more important in areas where people are more likely to have contact with someone in their group. ${ }^{4}$

Since the interaction term varies within zipcodes and years, we can also control for unobserved neighborhood-specific variables in a very complete way by including zipcode-year fixed effects. The zipcode-year effects subsume the vector $\mathrm{N}$ that was included in (1) above, and also subsume the "main effect" of contact availability. However, they do not quite subsume the YBAROWN and YBAROTHER variables because these are defined using the 11 months prior to the index woman's birth rather than the calendar year. Still, one expects the estimated effects of YBAROWN and YBAROTHER to be much attenuated in this specification.

Bertrand, Luttmer, and Mullainathan (2000) point out several possible problems with this identification strategy. First, if YBAROWN has a non-linear effect, then it may be captured by the interaction between CA and YBAROWN. Hence, we allow the main effect of YBAROWN to be

4. Calvo-Armengol and Jackson (2002) provide a theoretical justification for focusing on this interaction as a measure of network effects. 
non-linear by including two splines with break points at the bottom and top thirds of the distribution of YBAROWN for each racial/ethnic group. A second problem is that individuals who chose to live in areas with high contact availability may be different in unobserved respects from those who choose to live in other areas. For example, Hispanics who live in predominantly Hispanic neighborhoods may have different attitudes towards prenatal care than those who do not. The zipcode* year fixed effects included in the models help to control for these effects, but to the extent that this selection mechanism varies over time and across groups, it constitutes an unobserved group, area, and time-specific effect, which may bias estimates of network effects.

Hence we estimate an alternative to (2) which controls for one potential set of omitted variables, those that determine eligibility. To do this, we estimate models of the use of publicly funded prenatal care which control for the fraction of women in the "own" group who received a publicly funded delivery in the past 11 months. The idea is that since a hospital has a strong incentive to enroll eligible uninsured women, the fraction of women in a group who obtain public deliveries is a good proxy for the share that is eligible for public prenatal care.

These methods allow us to control for omitted variables that might drive exogenous and correlated effects in a more complete way than has been possible in previous studies using nonexperimental data. However, as Manski (2001) points out, even if we are able to find compelling evidence that behavior is correlated within groups, we would like to be able to say something about the reasons for these correlations.

One of the more interesting hypotheses about networks is that they affect takeup by sharing information about public programs. If the primary function of networks is to furnish information about publicly funded maternity care programs, then network effects should be more important for first pregnancies than for subsequent pregnancies. The reason is that after an eligible woman has already delivered once at public expense, then she knows about the existence of the public program, and about her own eligibility through her own personal experience. Moreover, since infants whose deliveries are paid for by Medicaid are covered for 60 days post-partum, eligible first time mothers 
have considerable time to learn about these programs. We therefore estimate (2) separately for first and second births, and compare the size of the estimated network effects.

We also estimate models with hospital*year fixed effects rather than zipcode*year fixed effects. There are fewer hospitals than zipcodes. For example, whites deliver in 936 zipcodes and 427 different hospitals. While the choice of hospital is obviously endogenous, these models can tell us how much of the estimated network effect is associated with the sorting of women who live in the same place into different hospitals. The extent to which women who live in the same place use different hospitals can be thought of as a group, area, and year-specific effect. If controlling for these variables significantly reduces the size of the estimated "network effects", then this suggests that the estimated effect is in fact picking up unobserved characteristics associated with the public health infrastructure available to each group; that is, that it is at least partly a neighborhood rather than a network effect.

Finally, we estimate separate models for foreign and native-born Hispanic women. We estimate two different versions of these models, one in which the YBARs are defined using all Hispanic women and one in which they are defined using only native/foreign born women. Given our maintained hypothesis that foreign-born women need more information about these programs, we expect that if information sharing drives network effects, we will find larger effects among foreign-born women when we define the network to include only foreign-born women.

Given that we do not know what the true geographical parameters of women's neighborhoods are, we also present results based on YBARs calculated using data aggregated to a somewhat higher level, the Minor Civil Division (MCD). MCDs are small clusters of 4 to 5 geographically contiguous 5-digit zipcodes. There are 371 MCDs in California (compared to 58 counties, and 936 zipcodes with at least one white birth) and 21 in Los Angeles County. For example, Burbank, Glendale, Pasadena, and Santa Monica are all MCDs within Los Angeles County. Moving from the zipcode to the MCD level may reduce the amount of random measurement error in the YBARs, resulting in larger coefficient estimates. On the other hand, to 
the extent that the MCD overstates the true size of the "neighborhood", network effects may be smaller when estimated at the MCD level.

Individuals in zipcodes with fewer than 50 births and/or fewer than 25 people in their racial/ethnic group giving birth during the preceding 11 months are excluded because we cannot estimate the YBARs precisely. This results in the loss of approximately $8 \%$ of the sample when we do the analysis at the zipcode level. For example, the analyses using whites include 936 zipcodes, those using Hispanics include 890 zipcodes, while those using blacks include 634. By allowing more individuals to be included in the comparison groups, moving to the MCD level increases the sample size by $7 \%$ for Hispanics, $16 \%$ for whites, and $24 \%$ for blacks. Appendix Table 2 shows the sample means for this "MCD-level" sample.

\section{c) Data Description}

Table 1 shows the means of the variables included in model (1) for first and second births, by race and ethnicity. The table shows that the largest share of births are to Hispanic women, followed by non-Hispanic whites. Blacks account for about $7 \%$ of births in California. It is remarkable that almost half of first time births in California are to single mothers. ${ }^{5}$ Table 1 shows that while over half of all first-time mothers in California use public payors for delivery, only slightly more than a third both use a public payor for prenatal care and begin care in the first trimester. This is despite the fact that close to $80 \%$ of all women begin prenatal care in the first trimester, suggesting a very different pattern among women using public programs.

There are large differences between mothers of different race and ethnic groups, both in terms of personal characteristics that one would expect to be associated with use of public programs, and in terms of the use of these programs. For example, while $71 \%$ of black first time mothers are

5. Up until 1997, California "inferred" marital status using other information on the birth certificate rather than asking it directly. However, we found that this change in procedures produced little change in the fraction of married women. For the sample as a whole, the fraction married was $36 \%$ in 1996 , and $40 \%$ in 1998 , while for Hispanics, the corresponding fractions were $39 \%$, and $43 \%$. 
single, only $27 \%$ of white mothers are. Also, while $63 \%$ of Hispanic mothers are foreign born, the fractions among non-Hispanic whites and blacks are $9 \%$ and $6 \%$ respectively. Hispanic women are most likely to use a public payor for delivery, and also most likely to use a public payor for prenatal care.

Table 1 also shows some of the ways in which the zipcodes women live in vary by race and ethnicity. These neighborhood characteristics are calculated using the Vital Statistics data, and so pertain to new mothers. For example, on average, Hispanic women live in zipcodes in which new mothers are less educated and which have relatively high fractions of births to teenage mothers. Hispanic women also live in zipcodes where $63 \%$ of first births are to Hispanic mothers and $22 \%$ of births are to other white mothers. In contrast, the average white woman lives in a zipcode in which $49 \%$ of births were to other white women, and $35 \%$ of births were to Hispanics.

A comparison of means for the first and second births, shows that in general they are quite similar, particularly in terms of maternal education and neighborhood characteristics. One interesting difference is that Hispanic and white women are slightly less likely to use public prenatal care in the first trimester for second births than for first births, while the reverse is true among black women. Also, second births are much less likely to be to single women among Hispanics and nonHispanic whites, and slightly less likely to be to single women among blacks.

Table 2 shows some of the variation in our outcome measures across zipcodes and over time, for first and second births, combined. The zipcodes in this table were chosen from counties that were deemed by the state to have shown the largest or the smallest increases in the "adequacy" of prenatal care utilization over time (Taylor and Chavez, 2000). ${ }^{6}$ Although they have similar income levels, the Long Beach zipcode was one of the areas that showed the greatest improvements, while the Sacramento zipcode showed the smallest improvements. For example, the table indicates that the fraction of women receiving first trimester prenatal care grew dramatically in this part of Long

6. The index of prenatal care adequacy that they use combines information about the timing of the initiation of prenatal care, and the number of visits adjusted for gestational age. 
Beach, especially among Hispanics, while the fraction of Hispanic women receiving first trimester prenatal care showed no change in Sacramento.

Table 2 suggests that some of the improvement in areas like Long Beach may have been due to increased utilization of public programs. For example, the fraction of women receiving publiclyfunded prenatal care in the first trimester increased for whites and blacks, and grew from $20 \%$ to $50 \%$ among Hispanics. In contrast, Sacramento showed no gains in the fraction of Hispanic women using public prenatal care programs.

Table 2 also indicates that there were tremendous changes in the ethnic composition of some zipcodes over this period, demonstrating the importance of controlling for this time-varying characteristic of neighborhoods in our models. For example, in this Long Beach zipcode, the number of white births fell from 381 to 74, while the number of Hispanic births increased from 333 to 571 over the twelve year period. Hence, improvement in prenatal care utilization in Long Beach occurred despite shifts in population that would, ceteris paribus, cause one to expect a decline in utilization since Hispanics are less likely to use prenatal care than whites on average.

Table 3 explores the notion of "contact availability". The sample was divided up into areas with low, medium, and high shares of women using the public service (i.e. into thirds), and into low, medium, and high shares of "own group" in the zip code. For example, a low share, low CA Hispanic woman lives in an area that is in the bottom third of the distribution of "share Hispanic" and in the bottom third of the distribution of Hispanic women using public services last period. Moving along a row shows what happens as contact availability increases, holding the share using public services last period relatively constant. As Table 3 shows, the probability that the given outcome is chosen increases with CA among Hispanics and whites, while among blacks there is no clear pattern.

\section{Estimates}

a) "Baseline” estimates 
Panels 1 through 3 of Table 4 show the estimated effect of YBAROWN in models of the form (1). Panel 1 suggests that YBAROWN has a very large effect on the use of public maternity care services. Panel 2 shows that this effect is slightly mitigated by the inclusion of YBAROTHER, which has a significant, but much smaller effect. Thus, Panel 2 shows that the index woman's behavior is much more highly correlated with the behavior of mothers from her own group, than with the behavior of mothers in other groups, lending some support to our definition of groups along racial and ethnic lines. Panel 3 shows that the estimated effect of YBAROWN is however, very sensitive to the inclusion of zipcode fixed effects. When zipcode fixed effects are added to (1), the estimated coefficient on YBAROWN is greatly reduced, though it remains large.

Appendix Table 2 shows the estimated coefficients on the other maternal and neighborhood characteristics included in the Panel 3 model. The effects of the other control variables are of the anticipated signs. For example, among Hispanics, being a teenage mother instead of a mother 45 or older increases the probability of publicly-funded prenatal care in the first trimester by 11 percentage points, while the effect of being a highschool dropout rather than having some college increases the probability by 18 percentage points. Thus, moving from an area with no Hispanic mothers to one in which all the mothers were Hispanic would have an effect of similar magnitude (but in the opposite direction) as increasing the level of education from less than high school to some college. It is interesting to compare the estimated effects of "networks" to those of maternal characteristics. For example, these estimates imply that moving from an area where few people used public services to one where virtually all new mothers did, would increase the probability of using public prenatal care services by 56 percent.

Panels 4 and 5 of Table 4 show estimates of models of the form (2), which include interactions between "contact availability" and YBAROWN as well as zipcode-year fixed effects. Panel 4 includes only the main effect of YBAROWN, while Panel 5 includes a spline in YBAROWN, as described above. However, there is no significant difference in the estimated coefficients on the key interaction term. Given the mean level of timely utilization of public 
prenatal care among Hispanic women of .442 , the estimated value of $\mathrm{a}_{4}$ in column 2 implies that moving from an area where there were no births to Hispanics to an area where all births were to Hispanics would increase the probability that a Hispanic woman used public prenatal care in the first trimester by 22.7 percentage points. For whites, the same thought experiment yields a much smaller effect of 8.5 percentage points, while for black women the comparable estimate is 30.4 percentage points. These estimates are clearly upper bounds on the effects that one would anticipate in practice, since women are unlikely to move from areas with no new mothers in their group to areas in which all of the new mothers are in their group. For example, a Hispanic woman moving from Long Beach 90805 to Sacramento 95822 would be moving from an area in which about $60 \%$ of the new mothers were Hispanic to one in which about $40 \%$ of new mothers were. Thus, one would have to divide the estimates above by a factor of five. ${ }^{7}$

The coefficients on the spline on YBAROWN in Panel 5 suggest that it does indeed have a non-linear effect on the propensity to use public programs. Note that YBAROWN is not subsumed by the zipcode* year fixed effects, because it is defined over a different time period than the calendar year (the 11 months prior to the birth). For Hispanics, the effect of increasing YBAROWN is positive when the spline is evaluated at the sample mean, while for whites and blacks it is negative. The most reasonable explanation for these different patterns may be that YBAROWN does indeed capture omitted characteristics of neighborhoods, which is the reason that we are focusing on the interaction between YBAROWN and CA.

\section{b) Alternative Specifications}

7. An alternative way to interpret these estimates is to ask how the network would multiply an exogenous shock to program participation. Following the calculations on pages 1039 and 1040 of Bertrand, Luttmer, and Mullainathan, the effect of an exogenous one percentage point change in program participation, is $\left[1 /\left(1-\mathrm{a}_{4}{ }^{*} \mathrm{CABAR}\right)\right]-1$, where $\mathrm{CABAR}$ is the mean contact availability for the group. Accordingly, network effects would increase the effect of the exogenous change by 48, 29, and 15 percent for Hispanics, whites, and blacks, respectively. These figures are in the same range as the 27 percent which Bertrand, Luttmer, and Mullainathan compute as a weighted average of the network effects over all language groups. 
Table 5 presents estimates from a number of variants of equation (2). For convenience, the coefficients on the interaction terms from Panel 5 of Table 4 are repeated in Panel 1. As discussed above, it is possible that the coefficient on the interaction will be biased if the variables associated with women choosing a particular area are also associated with their probability of using public prenatal care programs. This was the rationale for including zipcode*year fixed effects in equation (2). Panel 2 shows what happens when we replace these effects with simple year dummies. While the size of the estimated interactive effect is somewhat reduced, it remains statistically significant for both Hispanics and whites. However, it becomes insignificant in the models for blacks, suggesting that it is particularly important to control for omitted neighborhood-year effects in these models.

In order to test for the importance of an omitted group, area, and year specific effect, we next estimate models of the use of public prenatal care which are similar to (2) except that they also include the fraction of women in the "own" group who received a publicly funded delivery in the past 11 months. As discussed above, this variable is a good proxy for determinants of eligibility that may vary at the group, area and year level. The inclusion of this variable has very little effect on the estimated interaction effect, however, suggesting that once zipcode*year effects are included in the model, unobserved zipcode* year*group effects associated with eligibility for public deliveries are not driving the results for use of public prenatal care in the first trimester.

Since it is difficult to justify a particular geographic definition of a "neighborhood", we have also estimated models at the MCD level, rather than at the zipcode level. Since MCDs are larger than zipcodes, we loose fewer observations due to the lack of a comparison group of births, and so the usable sample size is larger as shown in panel 4 of Table 5. These regressions control for MCD*year effects rather than for zipcode*year effects. A comparison with panel 1 shows that the estimates are quite similar for Hispanics, somewhat smaller for whites, and that they become statistically insignificant for blacks. Given the similarity of the results for Hispanic women, we will estimate the models for native-born and foreign-born Hispanic women at the MCD level, in 
order to have larger cell sizes.

To summarize, we estimate several models of "network effects" including models which are similar to those of Bertrand, Luttmer, and Mullainathan in the sense that they focus on the interaction between "contact availability" and own group welfare use as a measure of network effects. The richness of our data allows us to move to a smaller level of aggregation and to control in a more complete way for potentially omitted characteristics of areas and years by adding zipcode*year effects. Our results are robust to including a proxy for group-area-year level determinants of eligibility for public delivery (e.g. average income in the group, area, and year). However, as Bertrand, Luttmer, and Mullainathan make clear, it is not possible to determine from models of this kind whether the measured effects represent information exchange, stigma, or some other characteristic of groups, areas and years. We turn to this question in the next section.

\section{c) Interpreting the Estimated Network Effects}

As discussed above, there are many women who have publicly funded deliveries in California who did not begin the use of publicly funded prenatal care in the first trimester. This may be because these women lack information about the programs, or because they do not know how to apply. Networks could act by passing on this type of information. However, mothers who have already had one delivery are likely to know a lot more about these programs than women who have not. Specifically, if they are eligible, they will find out about the program and how to get on it. Thus, if the main role of networks is to pass on this type of information, we should expect that networks will have much smaller effects for second births than they do for first births.

Panel 1 of Table 6 shows estimates similar to those in Panel 5 of Table 4 except that they are estimated using second births rather than first births. The coefficients on the interaction terms in the models for second births actually tend to be somewhat larger than the corresponding coefficients from models of first births, though the differences are not statistically significant. Thus, there is no evidence that estimated network effects are greater for first than for second births, as one might have 
expected if the estimated network effects reflected shared information about the existence of these public programs.

One additional piece of information we have on the birth certificates is the hospital where the woman delivered. Panel 2 of Table 6 shows models which include hospital*year effects rather than zipcode*year effects. These estimates examine the estimated network effects conditional on the choice of hospital. Recall that our baseline models with zipcode*year fixed effects control for the availability of hospitals. For example, if a woman lives near a hospital that is very accommodating to Medicaid mothers, then this is accounted for. In contrast, the models with hospital fixed effects control for the hospital that was actually chosen by the mother, given her own characteristics and those of her neighborhood.

The comparison of the baseline model with Panel 2 shows that controlling for the choice of the hospital of delivery reduces the size of estimated size of the network effect greatly. For whites, and for public deliveries among Hispanics, the estimated network effects become statistically insignificant. For publicly funded prenatal care among Hispanics, the estimated effect drops to a fifth of its previous value. For blacks, the effects remain statistically significant, but are reduced by more than half. Note that we do not know where women went to obtain prenatal care. In most cases, they would obtain this care outside of a hospital setting though it might be from a provider who was affiliated with a particular hospital. Thus, these results suggest that if we could control for the location where prenatal care services were received, we might reduce the size of the estimated network effects even further.

This striking result suggests that network effects in the use of public maternity services are largely "explained" by the choice of hospital where the woman delivers. This choice, in turn, is likely to reflect characteristics of the hospital which are changing over time, such as the quality of services offered to Medi-Cal mothers, whether translation services are provided, whether the hospital is affiliated with clinics attractive to low income women, and so on. The choice of hospital may also be affected by information sharing among women in a network, but without differences 
in hospital services to begin with, there would be no relevant information to share. It is also difficult to explain this result via "stigma". If the stigma a woman feels changes with the number of people in her group who use public services, then one would expect this to be largely independent of the hospital chosen.

Table 7 explores the results for Hispanics further by dividing women into those who are foreign-born and those who are native born. While most Hispanic women in California are of Mexican origin, there may nevertheless be large differences between the native born and more recent arrivals, and one might expect these women to belong to different social networks. Thus, in the first panel of Table 7, the "own group" is defined as all Hispanic women, while in the second panel of Table 7, the own group is defined as only native born or only foreign born Hispanic women, depending on the group the woman herself belongs to. These models are estimated are at the MCD level, in order to conserve sample size. As Table 5 showed, moving from the zipcode to the MCD level has little impact on the estimates for Hispanics.

The estimates for the use of publicly funded prenatal care are remarkably similar in the two panels. Thus, perhaps surprisingly, it does not appear to matter which definition of the "own group" is used, and there is little evidence that foreign-born women transmit information of special relevance to other foreign-born women through their networks. This result is consistent with the observation that hospitals seldom ask about a woman's immigration status, so that it is likely that hospitals treat foreign-born and native-born Hispanic women very similarly.

\section{Discussion and Conclusions}

We argue that it is interesting to look at network effects in the use of publicly funded prenatal care for two reasons. The first is the specific policy goal of improving the use of prenatal care among eligible women. Strong endogenous network effects would imply that outreach efforts which were concentrated in areas densely populated by target groups would have a greater impact than the same effort spread over a larger area. The second reason for examining network effects in 
this very specific context, is that it they may tell us something about the nature of these effects, and about factors that influence the takeup of social programs, more generally.

Like many others, we find evidence that behavior is highly correlated within groups defined using race/ethnicity and neighborhoods. These correlations persist even when we control for many unobserved characteristics via zipcode-year effects, and when we focus on the interactive effect of own group behavior and own group "contact availability”, as suggested by Bertrand, Luttmer, and Mullainathan (2000). In our view, the more important contribution of the paper is that the richness of our data allows us to go further, and to attempt to test the hypothesis that the estimated effects represent information sharing within groups.

We formulate three tests: First, we argue that if information sharing drives network effects, it should be more important for first births than for second births, given the fact that eligible pregnant women are likely to learn about public maternity care programs when they deliver the first time. We find, however, that the estimated effects are of similar magnitude for first and second births.

Second, we show that the estimated network effects are greatly reduced, often to statistical insignificance, when we control for the hospital of delivery. This suggests that variations across groups and areas in the use of public maternity care services may be driven more by the institutional infrastructure available to women of different groups, than by within-group interactions between the women. For example, the presence of Spanish-language enrollment assistance at a particular hospital or clinic might be a critical factor influencing takeup of the public program among Hispanic women in the surrounding area. Moreover, this result suggests that it is unlikely that the estimated network effects are driven by "stigma". If the stigma associated with using public programs falls as the number of group members using the program rises, then it is hard to see why this result should disappear when we control for hospital of delivery.

Third, we examine native-born and foreign-born Hispanic women separately. Our maintained hypothesis is that because of confusion surrounding the legality and consequences of 
using the services, foreign-born women require more information than native-born women in order to feel comfortable accessing public maternity care. Thus, one might expect networks to be more important for foreign-born than for native-born Hispanic women. However, we find little evidence that this is the case, suggesting once again that the estimated network effects are unlikely to be driven by information sharing. Instead, the similarity in the estimates for native-born and foreignborn women is consistent with the observation that providers of medical care seldom ask about immigration status in California.

Our results suggest that it is extremely difficult to identify endogenous network effects (i.e. causal effects of one person's behavior on other members of his or her group) in publicly available survey data because of the infeasibility of adequately controlling for all of the omitted group, area, and time-specific variables that affect behavior. More positively, our results indicate that we can gain further understanding of group-level correlations in the propensity to take up public programs by examining the way that relevant institutions, such as hospitals, treat members of different groups; or alternatively, how members of different groups respond to similar treatment. We currently have little systematic data about the way that most public programs are administered "on the ground". While this study focuses on a particular program in a specific location, the results suggest that such administrative information could help us to understand group and location-level differences in the propensity to participate in public programs more generally. 


\section{References}

Aizer, Anna. "Covering Kids: Improving the Health Insurance Coverage of Poor Children", xerox, Dept. of Economics UCLA, August 2001.

Aizer, Anna. 2002. “Got Health? Advertising, Medicaid, and Child Health?”, UCLA xerox, January 2002.

Alexander, Greg. R. and Carol C. Korenbrot. "The Role of Prenatal Care in Preventing Low Birth weight", The Future of Children v5 \#1, Spring 1995.

Armson, Tony and Jean-Marie Moutquin. "Preterm Birth-Secondary and Tertiary Prevention" in Prevention of Low Birth Weight in Canada" $2^{\text {nd }}$ Edition (Toronto: Perinatal Education Program of Eastern Ontario) 1998.

Aved, Barbara M. et al., "Barriers to Prenatal Care for Low-Income Women," The Western Journal of Medicine, 158 \#5 (May 1993) 493-498.

Bernstein, S., "Women denied epidurals file class-action lawsuits", Los Angeles Times, Thursday June 17, 1999.

Bertrand, Marianne, Erzo Luttmer, and Sendhil Mullainathan. "Network Effects and Welfare Cultures", Quarterly Journal of Economics, v CXV, August 2000, 1019-1056.

Blank, Rebecca and David Card. "Recent Trends in Insured and Uninsured Unemployment: Is There an Explanation?," Quarterly Journal of Economics 106, November 1991, 1157-1190.

Blank, Rebecca and Patricia Ruggles. "When Do Women Use AFDC \& Food Stamps? The Dynamics of Eligibility vs. Participation," Journal of Human Resources, 31 \#1, Winter, 1996, 57-89.

Borjas, George. "Ethnic Capital and Intergenerational Mobility", Quarterly Journal of Economics CVII, 1992, 123-150.

Borjas, George. "Ethnicity, Neighborhoods, and Human-Capital Externalities", American Economic Review, LXXXV, 1995, 365-390.

Borjas, George and Lynette Hilton. "Immigrant Participation in Means-Tested Entitlement Programs", Quarterly Journal of Economics, v111 \#2, May 1996, 575-604.

Calvo-Armengol, Antoni and Matthew Jackson. "Social Networks and Resulting Patterns and Dynamics of Employment and Wages", California Institute of Technology xerox, March 2002.

Currie, Janet and Jeffrey Grogger. "Medicaid Expansions and Welfare Contractions: Offsetting Effects on Prenatal Care and Infant Health", Journal of Health Economics, v21 \#2, March, 2002, 313-335.

Currie, Janet and Jonathan Gruber, "Health insurance eligibility and Child Health: Lessons from Recent Expansions of the Medicaid program", Quarterly Journal of Economics, May, 431-466, $1996 a$.

Currie, Janet, and Jonathan Gruber. "Saving Babies: The Efficacy and Cost of Recent Changes in the Medicaid Eligibility of Pregnant Women," Journal of Political Economy, December 1996b. 
Daponte, Beth, Seth Sanders, and Lowell Taylor. "Why Do Low Income Households Not Use Food Stamps: Evidence From an Experiment", Journal of Human Resources, 34 \#3, Summer 1999, 612 628.

Duflo, Esther and Emmanuel Saez. "The Role of Information and Social Interaction in Retirement Plan Decisions: Evidence from a Randomized Experiment", xerox, Dept. of Economics, Harvard University, 2001.

Duggan, Mark. "Hospital Ownership and Public Medical Spending", Quarterly Journal of Economics, v 115 \#4, November 2000, 1343-1373.

Ellwood, Marilyn and Genevieve Kenney. "Medicaid and Pregnant Women: Who is Being Enrolled and When?", Health Care Financing Review, 17 \#2, 1995, 7-28.

Fossett, James W., et al. "Medicaid and Access to Child Health Care in Chicago", Journal of Health Politics, Policy, and Law, XVII, 1992, 273-298.

Frank, Richard, Donna Storbino, David Salkever, Catherine Jackson. "Updated Estimates of the Impact of Prenatal Care on Birth weight Outcomes by Race," NBER Working Paper \#3624, Cambridge, February 1991.

Kalmuss, Debra and Katherine Fennelly, "Barriers to Prenatal Care Among Low-Income Women in New York City" Family Planning Perspectives, 22 \#5, Sept./Oct., 1990, 215-231.

Katz, Lawrence, Jeffrey Kling, and Jeffrey Leibman. "Moving to Opportunity in Boston: Early Results of a Randomized Mobility Experiment", Quarterly Journal of Economics, CXVI, \#2, May 2001, 607-645.

Kogan, Michael D. et al. "Relation of the Content of Prenatal Care to the Risk of Low Birth weight", Journal of the American Medical Association, 221 \#17, May 4, 1994, 1340-1345.

Korenbrot, Carol C. "Use of Medicaid for Prenatal Care by Immigrants in CA", Journal of Immigrant Health, forthcoming.

Ludwig, Jens, Greg J. Duncan, and Paul Hirschfield. "Urban Poverty and Juvenile Crime: Evidence from a Randomized Housing Mobility Experiment", Quarterly Journal of Economics, CXVI \#2, May 2001 655-680.

Manski, Charles. "Identification of Endogenous Social Effects: The Reflection Problem", The Review of Economic Studies, 60 \#3, July 1993, 531-542.

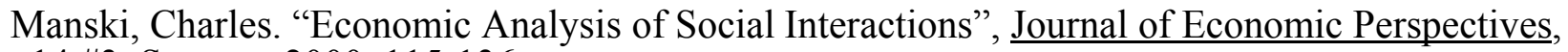
v14 \#3, Summer 2000, 115-136.

Marbella, Anne, Veerappa Chetty and Peter Layde, "Neonatal Hospital Lengths of Stay, Readmissions and Charges", Pediatrics, 101 \#1, January 1998, 32-36.

Massey, Douglas S. and Nancy Denton, American Apartheid, (Cambridge MA: Harvard University Press, 1993).

Moffitt, Robert. "An Economic Model of Welfare Stigma", American Economic Review, 73 \#5, December 1983, 1023-1035. 
Moffitt, Robert. "Policy Interventions, Low-Level Equilibria and Social Interactions" in Steven Durlauf and Peyton Young (eds.) Social Dynamics (Cambridge MA: MIT Press) forthcoming.

Nario, Nora. Aim Fact Book (Sacramento CA: Managed Risk Medical Insurance Board) 1998.

Norton, Stephen, Genevieve Kenney and Marilyn Rymer Ellwood. "Medicaid Coverage of Maternity Care for Aliens in California", Family Planning Perspectives, v28 \#3, May/June 1996, 108-112.

Public Citizen. "Public Citizen's Research Group Report on Questionable Hospitals" (Washington D.C.: Public Citizen) July, 2001.

Rosenzweig, Mark and T. Paul Schultz. "The Behavior of Mothers as Inputs to Child Health: The Determinants of Birth Weight, Gestation, and Rate of Fetal Growth," in Economic Aspects of Health, Victor Fuchs (ed.), University of Chicago Press: Chicago, 1982.

Rosenzweig, Mark and T. Paul Schultz. "Estimating a Household Production Function: Heterogeneity, the Demand for Health Inputs, and Their Effects on Birth Weight," Journal of Political Economy, 91, October 1983, 723-746.

Rosenzweig, Mark and T. Paul Schultz. "The Stability of Household Production Technology, A Replication," The Journal of Human Resources, 23, Fall 1988, 535-549.

Saywell, et al. "Hospital and Patient Characteristics of Uncompensated Hospital Care: Policy Implications," Journal of Health Politics, Policy, and Law, 14, 1989, 287-307.

Taylor, Don and Gilberto Chavez. Atlas of Prenatal Care Utilization, California-1998 (Sacramento: California Dept. of Health Services Maternal and Child Health Branch), October 2000.

U.S. Dept. of Health and Human Services. Healthy People 2010: Understanding and Improving Health, $2^{\text {nd }}$ Edition (Washington D.C.: GPO) November 2000.

U.S. General Accounting Office, Health Care Reform: Potential Difficulties in Determining Eligibility for Low Income People, (Washington D.C.: Government Printing Office, July, 1994) document number GAO/HEHS-94

Yoo, Grace J. and Lisa Park. 2001. “The Impact of Public Charge on Immigrant Women's Access to Medi-Cal" (San Francisco: The California Program on Access to Care at the California Policy Research Center) April 2001. 
Table 1 - Sample Means for First and Second Births, By Race

\begin{tabular}{|c|c|c|c|c|c|c|}
\hline \multirow[b]{2}{*}{ Maternal Characteristics } & \multicolumn{3}{|c|}{ First Births } & \multicolumn{3}{|c|}{ Second Births } \\
\hline & Hispanic & White & Black & Hispanic & White & Black \\
\hline Public delivery & 0.656 & 0.256 & 0.553 & 0.612 & 0.231 & 0.553 \\
\hline Public prenatal 1st trimester & 0.442 & 0.188 & 0.399 & 0.409 & 0.169 & 0.406 \\
\hline Prenatal 1st trimester & 0.745 & 0.880 & 0.780 & 0.751 & 0.888 & 0.793 \\
\hline \multirow[t]{2}{*}{ Maternal age } & 22.327 & 26.492 & 22.278 & 25.459 & 29.007 & 25.655 \\
\hline & $(0.005)$ & $(0.007)$ & $(0.016)$ & $(0.006)$ & $(0.007)$ & $(0.018)$ \\
\hline \multirow[t]{2}{*}{ Maternal education } & 10.519 & 13.691 & 12.445 & 10.286 & 13.698 & 12.736 \\
\hline & $(0.003)$ & $(0.003)$ & $(0.006)$ & $(0.004)$ & $(0.003)$ & $(0.006)$ \\
\hline Single & 0.502 & 0.267 & 0.711 & 0.381 & 0.163 & 0.609 \\
\hline Foreign born & 0.629 & 0.093 & 0.052 & 0.687 & 0.094 & 0.056 \\
\hline \multicolumn{7}{|l|}{ Neighborhood Characteristics } \\
\hline \multirow[t]{2}{*}{ Share of own group with public delivery } & 0.650 & 0.317 & 0.619 & 0.652 & 0.318 & 0.621 \\
\hline & $(0.0002)$ & $(0.0002)$ & $(0.0004)$ & $(0.0002)$ & $(0.0002)$ & $(0.0005)$ \\
\hline \multirow{2}{*}{$\begin{array}{l}\text { Share of own group with public prenatal } \\
\text { 1st trimester }\end{array}$} & 0.414 & 0.222 & 0.428 & 0.419 & 0.222 & 0.429 \\
\hline & $(0.0001)$ & $(0.0002)$ & $(0.0003)$ & $(0.0002)$ & $(0.0002)$ & $(0.0004)$ \\
\hline \multirow[t]{2}{*}{ Share of other group with public delivery } & 0.4500 & 0.522 & 0.610 & 0.4530 & 0.5200 & 0.6110 \\
\hline & $(0.0002)$ & $(0.0002)$ & $(0.0005)$ & $(0.0002)$ & $(0.0002)$ & $(0.001)$ \\
\hline \multirow{2}{*}{$\begin{array}{l}\text { Share of other group with public prenatal } \\
\text { 1st trimester }\end{array}$} & 0.3100 & 0.332 & 0.390 & 0.3130 & 0.3310 & 0.3900 \\
\hline & $(0.0001)$ & $(0.0002)$ & $(0.0004)$ & $(0.0002)$ & $(0.0002)$ & $(0.0004)$ \\
\hline \multirow[t]{2}{*}{ Share Asian } & 0.047 & 0.056 & 0.059 & 0.047 & 0.053 & 0.059 \\
\hline & $(0.0001)$ & $(0.0001)$ & $(0.0002)$ & $(0.0001)$ & $(0.0001)$ & $(0.0002)$ \\
\hline \multirow[t]{2}{*}{ Share black } & 0.070 & 0.056 & 0.264 & 0.071 & 0.054 & 0.258 \\
\hline & $(0.0001)$ & $(0.0001)$ & $(0.001)$ & $(0.0001)$ & $(0.0001)$ & $(0.001)$ \\
\hline \multirow[t]{2}{*}{ Share Hispanic } & 0.628 & 0.350 & 0.456 & 0.634 & 0.350 & 0.458 \\
\hline & $(0.0002)$ & $(0.0002)$ & $(0.001)$ & $(0.0003)$ & $(0.0003)$ & $(0.001)$ \\
\hline \multirow[t]{2}{*}{ Share white } & 0.219 & 0.492 & 0.176 & 0.214 & 0.497 & 0.181 \\
\hline & $(0.0002)$ & $(0.0002)$ & $(0.001)$ & $(0.0002)$ & $(0.0003)$ & $(0.001)$ \\
\hline \multirow[t]{2}{*}{ Share of teen mothers } & 0.149 & 0.118 & 0.162 & 0.149 & 0.119 & 0.162 \\
\hline & $(0.00004)$ & $(0.0001)$ & $(0.0001)$ & 0.0000 & $(0.0001)$ & $(0.0001)$ \\
\hline \multirow[t]{2}{*}{ Share of single mothers } & 0.409 & 0.307 & 0.479 & 0.411 & 0.306 & 0.477 \\
\hline & $(0.0001)$ & $(0.0001)$ & $(0.0003)$ & $(0.0001)$ & $(0.0001)$ & $(0.0004)$ \\
\hline \multirow[t]{2}{*}{ Share of foreign born mothers } & 0.532 & 0.334 & 0.442 & 0.534 & 0.326 & 0.440 \\
\hline & $(0.0002)$ & $(0.0002)$ & $(0.0005)$ & $(0.0002)$ & $(0.0002)$ & $(0.001)$ \\
\hline \multirow[t]{2}{*}{ Average maternal education } & 10.435 & 11.549 & 10.741 & 10.425 & 11.559 & 10.735 \\
\hline & $(0.001)$ & $(0.001)$ & $(0.003)$ & $(0.001)$ & $(0.001)$ & $(0.003)$ \\
\hline \multirow[t]{2}{*}{ Average maternal age } & 25.991 & 26.756 & 25.755 & 25.990 & 26.742 & 25.738 \\
\hline & $(0.001)$ & $(0.002)$ & $(0.002)$ & $(0.001)$ & $(0.002)$ & $(0.002)$ \\
\hline Observations & 880305 & 761813 & 124553 & 713201 & 598786 & 96054 \\
\hline
\end{tabular}


Table 2: Changes in the Use of Public Maternity Care, 1989-2000

\begin{tabular}{|c|c|c|c|c|c|c|}
\hline & \multicolumn{2}{|c|}{ State of California } & \multirow{2}{*}{\multicolumn{2}{|c|}{$\begin{array}{l}\text { Long Beach } \\
90805\end{array}$}} & \multicolumn{2}{|c|}{ Sacramento } \\
\hline zipcode & & & & & & \\
\hline \multirow[t]{2}{*}{ Median HH income, 1989} & & & \multicolumn{2}{|c|}{29607} & \multicolumn{2}{|c|}{30106} \\
\hline & 1989 & 2000 & 1989 & 2000 & 1989 & 2000 \\
\hline \multicolumn{7}{|l|}{ Hispanic } \\
\hline Number of Births & 128600 & 151719 & 333 & 571 & 104 & 105 \\
\hline$\%$ public delivery & $55 \%$ & $63 \%$ & $50 \%$ & $64 \%$ & $63 \%$ & $60 \%$ \\
\hline$\%$ public prenatal in first trimester & $20 \%$ & $48 \%$ & $19 \%$ & $49 \%$ & $40 \%$ & $41 \%$ \\
\hline$\%$ prenatal in first trimester & $64 \%$ & $80 \%$ & $65 \%$ & $82 \%$ & $74 \%$ & $75 \%$ \\
\hline \multicolumn{7}{|l|}{ White } \\
\hline Number of Births & 141265 & 74429 & 381 & 74 & 113 & 52 \\
\hline$\%$ public delivery & $29 \%$ & $30 \%$ & $33 \%$ & $49 \%$ & $42 \%$ & $35 \%$ \\
\hline$\%$ public prenatal in first trimester & $18 \%$ & $23 \%$ & $20 \%$ & $39 \%$ & $30 \%$ & $21 \%$ \\
\hline$\%$ prenatal in first trimester & $81 \%$ & $87 \%$ & $78 \%$ & $86 \%$ & $86 \%$ & $77 \%$ \\
\hline \multicolumn{7}{|l|}{ Black } \\
\hline Number of Births & 28084 & 18067 & 265 & 230 & 125 & 57 \\
\hline$\%$ public delivery & $57 \%$ & $54 \%$ & $47 \%$ & $43 \%$ & $63 \%$ & $56 \%$ \\
\hline$\%$ public prenatal in first trimester & $34 \%$ & $41 \%$ & $33 \%$ & $36 \%$ & $40 \%$ & $37 \%$ \\
\hline$\%$ prenatal in first trimester & $70 \%$ & $81 \%$ & $72 \%$ & $84 \%$ & $75 \%$ & $77 \%$ \\
\hline
\end{tabular}

Note: Numbers are based on first and second births, excluding college educated women. 
Table 3: Impact of Contact Availability on Outcomes

\begin{tabular}{|c|c|c|c|c|c|c|}
\hline \multirow[b]{2}{*}{ Hispanic } & \multicolumn{3}{|c|}{ Public Delivery } & \multicolumn{3}{|c|}{ Public Prenatal, First Trimester } \\
\hline & Low CA & Moderate CA & High CA & Low CA & Moderate CA & High CA \\
\hline$\overline{\text { Low YBAR }}$ & 0.467 & 0.536 & 0.568 & 0.287 & 0.328 & 0.333 \\
\hline Moderate YBAR & 0.643 & 0.669 & 0.695 & 0.409 & 0.444 & 0.476 \\
\hline High Ybar & 0.760 & 0.797 & 0.810 & 0.527 & 0.572 & 0.592 \\
\hline White & Low CA & Moderate CA & High CA & Low CA & Moderate CA & High CA \\
\hline Low YBAR & 0.122 & 0.111 & 0.101 & 0.091 & 0.082 & 0.072 \\
\hline Moderate YBAR & 0.223 & 0.232 & 0.249 & 0.164 & 0.165 & 0.172 \\
\hline High YBAR & 0.41 & 0.435 & 0.469 & 0.299 & 0.317 & 0.352 \\
\hline Black & Low CA & Moderate CA & High CA & Low CA & Moderate CA & High CA \\
\hline Low YBAR & 0.402 & 0.407 & 0.43 & 0.29 & 0.295 & 0.296 \\
\hline Moderate YBAR & 0.55 & 0.569 & 0.552 & 0.393 & 0.395 & 0.398 \\
\hline High YBAR & 0.715 & 0.698 & 0.67 & 0.515 & 0.509 & 0.496 \\
\hline
\end{tabular}

Note: The sample was divided into thirds for low, medium, and high contact availability, and low, medium, and high levels of YBAR, where YBAR is either public delivery (in the first 3 columns) or public prenatal care that commenced in the first trimester (in the last 3 columns). Means of YBAR were then computed for each cell, using the sample of first and second births. 
Table 4: Estimates of "Network Effects"

1. No zipcode fixed effects

Share own group with outcome

\author{
Hispanic \\ Public Public \\ Delivery Prenatal
}

\author{
White \\ Public Public \\ Delivery Prenatal
}

Public
Delivery

Black

$\begin{array}{cccccc}0.641 & 0.752 & 0.72 & 0.757 & 0.693 & 0.688 \\ {[0.009]} & {[0.009]} & {[0.013]} & {[0.014]} & {[0.018]} & {[0.020]}\end{array}$

R-squared

$0.24 \quad 0.11$

0.31

0.19

0.18

0.09

2. No zipcode fixed effects, controls for "others"

$\begin{array}{lccccccc}\text { Share own group with outcome } & 0.612 & 0.724 & & 0.652 & 0.707 & 0.597 & 0.562 \\ & {[0.010]} & {[0.011]} & {[0.013]} & {[0.014]} & {[0.019]} & {[0.022]} \\ \text { Share other group with outcome } & 0.072 & 0.069 & 0.141 & 0.087 & 0.289 & 0.263 \\ & {[0.009]} & {[0.011]} & {[0.010]} & {[0.011]} & {[0.023]} & {[0.022]} \\ \text { R-squared } & 0.24 & 0.11 & 0.31 & 0.19 & 0.18 & 0.09 \\ & & & & & & \\ \text { 3. Zipcode fixed effects, controls for "others" } & & & & & \\ \text { Share of own group w/outcome } & 0.357 & 0.56 & 0.309 & 0.299 & 0.234 & 0.148 \\ & {[0.015]} & {[0.012]} & {[0.020]} & {[0.017]} & {[0.024]} & {[0.024]} \\ \text { Share of other group w/outcome } & 0.111 & 0.143 & 0.123 & 0.117 & 0.222 & 0.253 \\ & {[0.011]} & {[0.014]} & {[0.011]} & {[0.009]} & {[0.034]} & {[0.024]} \\ \text { R-squared } & 0.24 & 0.11 & 0.32 & 0.2 & 0.19 & 0.1\end{array}$

4. Zipcode-year fixed effects, controls for "others", interaction

\begin{tabular}{|c|c|c|c|c|c|c|}
\hline Share own *percent own & $\begin{array}{c}0.266 \\
{[0.051]}\end{array}$ & $\begin{array}{c}0.455 \\
{[0.057]}\end{array}$ & $\begin{array}{c}0.375 \\
{[0.048]}\end{array}$ & $\begin{array}{c}0.402 \\
{[0.052]}\end{array}$ & $\begin{array}{c}0.615 \\
{[0.152]}\end{array}$ & $\begin{array}{c}0.798 \\
{[0.164]}\end{array}$ \\
\hline Share own & 0.096 & 0.027 & -0.15 & -0.18 & -0.128 & -0.246 \\
\hline & [0.027] & [0.032] & [0.024] & [0.026] & [0.042] & [0.045] \\
\hline Share other & 0.159 & 0.229 & 0.184 & 0.174 & 0.189 & 0.316 \\
\hline & [0.014] & [0.017] & [0.010] & [0.010] & [0.036] & [0.041] \\
\hline R-squared & 0.25 & 0.12 & 0.32 & 0.21 & 0.2 & 0.12 \\
\hline 5. Zipcode-year fixed effects, controls fo & "others", & ine in inte & & & & \\
\hline Share own group w/outcome ${ }^{*}$ & 0.253 & 0.513 & 0.428 & 0.453 & 0.59 & 0.761 \\
\hline Share own group & [0.054] & [0.058] & [0.048] & [0.053] & [0.154] & [0.167] \\
\hline Share own w/outcome & 0.092 & 0.081 & -0.361 & -0.422 & -0.177 & -0.322 \\
\hline & [0.027] & [0.035] & [0.038] & [0.043] & [0.057] & [0.069] \\
\hline Share own w/outcome- middle third & 0.077 & -0.085 & 0.158 & 0.21 & 0.121 & 0.161 \\
\hline & [0.032] & [0.040] & [0.039] & [0.046] & [0.089] & [0.110] \\
\hline Share own w/outcome - top third & -0.153 & -0.137 & 0.132 & 0.091 & -0.076 & -0.081 \\
\hline & [0.046] & [0.049] & [0.030] & [0.034] & [0.098] & [0.104] \\
\hline Share other group w/outcome & 0.154 & 0.225 & 0.186 & 0.174 & 0.187 & 0.317 \\
\hline & [0.014] & [0.017] & [0.010] & {$[0.010]$} & [0.037] & [0.041] \\
\hline R-squared & 0.25 & 0.12 & 0.32 & 0.21 & 0.2 & 0.12 \\
\hline Observations & 880305 & 861634 & 761813 & 754615 & 124553 & 122198 \\
\hline
\end{tabular}

Robust standard errors in parentheses. Models 1 to 3 include year effects, and neighborhood characteristics: the share of teen mothers, share of foreign-born mothers, mean maternal education, mean maternal age, and the share of single mothers. All regressions include the following maternal characteristics: whether or not the mother is foreign born, single, a teen, 20-29, 30-39, 40-45, a high school dropout, or a high school graduate. 
Table 5: Alternative Specifications

\begin{tabular}{|c|c|c|c|c|c|c|}
\hline 1. Base Regression & $\begin{array}{c}\text { Hisp. } \\
\text { Pub } \\
\text { Delivery }\end{array}$ & $\begin{array}{c}\text { Hisp. } \\
\text { Pub Pren. } \\
\text { First Tri }\end{array}$ & $\begin{array}{c}\text { White } \\
\text { Pub } \\
\text { Delivery }\end{array}$ & $\begin{array}{c}\text { White } \\
\text { Pub Pren. } \\
\text { First Tri }\end{array}$ & $\begin{array}{c}\text { Black } \\
\text { Pub } \\
\text { Delivery }\end{array}$ & $\begin{array}{l}\text { Black } \\
\text { Pub Pren. } \\
\text { First Tri }\end{array}$ \\
\hline Share own group w/outcome ${ }^{*}$ & 0.253 & 0.513 & 0.428 & 0.453 & 0.59 & 0.761 \\
\hline share own group & [0.054] & {$[0.058]$} & [0.048] & {$[0.053]$} & [0.154] & {$[0.167]$} \\
\hline Observations & 880305 & 861634 & 761813 & 754615 & 124553 & 122198 \\
\hline R-squared & 0.25 & 0.12 & 0.32 & 0.21 & 0.2 & 0.12 \\
\hline
\end{tabular}

\section{Without zipcode fixed effects}

\begin{tabular}{|c|c|c|c|c|c|c|}
\hline Share own group w/outcome ${ }^{*}$ & 0.269 & 0.302 & 0.131 & 0.175 & 0.024 & -0.039 \\
\hline share own group & [0.032] & [0.031] & [0.057] & [0.070] & [0.100] & [0.106] \\
\hline Observations & 880305 & 861634 & 761813 & 754615 & 124553 & 122198 \\
\hline R-squared & 0.24 & 0.11 & 0.31 & 0.19 & 0.18 & 0.09 \\
\hline
\end{tabular}

3. Control for Public Deliveries

\begin{tabular}{|c|c|c|c|}
\hline Share own group w/outcome* & 0.574 & 0.445 & 0.746 \\
\hline share own group & {$[0.058]$} & [0.053] & [0.167] \\
\hline Observations & 861634 & 754615 & 122198 \\
\hline R-squared & 0.12 & 0.21 & 0.12 \\
\hline
\end{tabular}

4. MCD-level Analysis

\begin{tabular}{lcccccc}
\hline Share own group w/outcome & 0.191 & 0.459 & 0.228 & 0.172 & 0.252 & 0.147 \\
*share own group & {$[0.057]$} & {$[0.054]$} & {$[0.060]$} & {$[0.064]$} & {$[0.383]$} & {$[0.435]$} \\
Observations & 942980 & 922945 & 863703 & 855761 & 152564 & 149778 \\
R-squared & 0.24 & 0.11 & 0.3 & 0.18 & 0.19 & 0.1
\end{tabular}

Note: Except for the difference noted in the panel heading, these regressions are all similar to those shown in Panel 5 of Table 4. 
Table 6: Tests of the "Information Hypothesis"

\begin{tabular}{|c|c|c|c|c|c|}
\hline Hisp. & Hisp. & White & White & Black & Black \\
\hline $\begin{array}{c}\text { Pub } \\
\text { Delivery }\end{array}$ & $\begin{array}{l}\text { Pub Pren. } \\
\text { First Tri }\end{array}$ & $\begin{array}{c}\text { Pub } \\
\text { Delivery }\end{array}$ & $\begin{array}{l}\text { Pub Pren. } \\
\text { First Tri }\end{array}$ & $\begin{array}{c}\text { Pub } \\
\text { Delivery }\end{array}$ & $\begin{array}{c}\text { Pub Pren. } \\
\text { First Tri }\end{array}$ \\
\hline
\end{tabular}

1. Model estimated using 2nd births

\begin{tabular}{lcccccc}
\hline Share own group w/outcome & 0.225 & 0.606 & 0.455 & 0.629 & 0.882 & 1.065 \\
*share own group & {$[0.062]$} & {$[0.065]$} & {$[0.051]$} & {$[0.056]$} & {$[0.176]$} & {$[0.191]$} \\
Observations & 713201 & 698162 & 598786 & 592498 & 96054 & 93977 \\
R-squared & 0.27 & 0.13 & 0.37 & 0.23 & 0.26 & 0.14
\end{tabular}

2. Model estimated using 1 st births, including Hospital*year FE

\begin{tabular}{|c|c|c|c|c|c|c|}
\hline Share own group w/outcome ${ }^{*}$ & -0.082 & 0.108 & 0.062 & 0.05 & 0.176 & 0.305 \\
\hline share own group & [0.051] & [0.032] & [0.051] & [0.065] & [0.088] & [0.111] \\
\hline Observations & 879253 & 860785 & 758745 & 751538 & 124222 & 121932 \\
\hline R-squared & 0.5 & 0.24 & 0.49 & 0.34 & 0.57 & 0.33 \\
\hline
\end{tabular}

Notes: Other than the differences noted in the panel headings, these regressions are similar to the "base regressions" shown in Panel 5 of Table 4. 
Table 7: Hispanic Mothers Stratified by Native vs. Foreign Born, MCD level

Panel 1: Share Own=Hispanic Mothers

Native born

Public Public Pren.

Delivery First Tri

Share of own group w/outcome*share Hispanic

0.315

0.407

[0.104] [0.091]

Observations

350790

344989

R-squared

0.23

0.12

\begin{tabular}{cc} 
& Foreign born \\
\hline Public & Public Pren. \\
Delivery & First Tri \\
\hline 0.022 & 0.348 \\
{$[0.074]$} & {$[0.071]$} \\
592216 & 577982 \\
0.19 & 0.09
\end{tabular}

Panel 2: Share Own=Native or Foreign born Hispanic Mothers

Share own group with outcome* share own

$\begin{array}{cc}-0.04 & 0.346 \\ {[0.106]} & {[0.117]} \\ 345814 & 340084 \\ 0.23 & 0.12\end{array}$

0.235

0.376

[0.050]

[0.036]

Observations

0.23

590505

576323

R-squared

0.12

0.19

0.09

Note: Regression models are similar to those in Panel 4 of Table 4 in that they include MCD*year effects instead of zipcode*year effects. 


\section{Appendix Table 1: Means for Third Births by Race}

\section{Maternal Characteristics}

Public delivery

Public prenatal 1st trimester

Prenatal 1st trimester

Maternal age

Maternal education

Single

Foreign born

Neighborhood Characteristics

Share of own group with public delivery

Share of own group with public prenatal 1st trimester

Share of other group with public delivery

Share of other group with public prenatal

1st trimester

Share Asian

Share black

Share Hispanic

Share white

Share of teen mothers

Share of single mothers

Share of foreign born mothers

Average maternal education

Average maternal age

\begin{tabular}{|c|c|c|}
\hline Hispanic & White & Black \\
\hline 0.619 & 0.271 & 0.598 \\
\hline 0.403 & 0.189 & 0.422 \\
\hline 0.730 & 0.853 & 0.761 \\
\hline 28.072 & 30.494 & 27.635 \\
\hline (0.005) & $(0.006)$ & $(0.016)$ \\
\hline 9.622 & 13.402 & 12.576 \\
\hline$(0.004)$ & $(0.003)$ & $(0.005)$ \\
\hline 0.353 & 0.174 & 0.607 \\
\hline 0.726 & 0.094 & 0.053 \\
\hline 0.655 & 0.317 & 0.623 \\
\hline$(0.0001)$ & $(0.0002)$ & $(0.0004)$ \\
\hline 0.417 & 0.221 & 0.431 \\
\hline (0.0001) & $(0.0002)$ & $(0.0003)$ \\
\hline 0.456 & 0.521 & 0.624 \\
\hline$(0.0002)$ & $(0.0002)$ & $(0.0005)$ \\
\hline 0.315 & 0.330 & 0.398 \\
\hline$(0.0001)$ & $(0.0002)$ & $(0.0004)$ \\
\hline 0.047 & 0.053 & 0.057 \\
\hline$(0.0001)$ & $(0.0001)$ & $(0.0002)$ \\
\hline 0.072 & 0.055 & 0.281 \\
\hline (0.0001) & $(0.0001)$ & $(0.001)$ \\
\hline 0.640 & 0.344 & 0.461 \\
\hline$(0.0002)$ & $(0.0002)$ & $(0.001)$ \\
\hline 0.208 & 0.502 & 0.159 \\
\hline$(0.0002)$ & $(0.0002)$ & (0.001) \\
\hline 0.151 & 0.119 & 0.165 \\
\hline$(0.00004)$ & $(0.0001)$ & $(0.0001)$ \\
\hline 0.414 & 0.305 & 0.492 \\
\hline (0.0001) & $(0.0001)$ & (0.0003) \\
\hline 0.539 & 0.325 & 0.446 \\
\hline$(0.0002)$ & $(0.0002)$ & (0.001) \\
\hline 10.383 & 11.566 & 10.682 \\
\hline (0.001) & $(0.001)$ & $(0.003)$ \\
\hline 25.941 & 26.730 & 25.690 \\
\hline$(0.001)$ & $(0.002)$ & $(0.002)$ \\
\hline 859850 & 708289 & 106912 \\
\hline
\end{tabular}

Observations 


\begin{tabular}{|c|c|c|c|}
\hline \multicolumn{4}{|c|}{ Appendix Table 2: Sample Means for First Births, MCD Sample } \\
\hline Maternal Characteristics & Hispanic & White & Black \\
\hline$\overline{\text { Public delivery }}$ & 0.655 & 0.247 & 0.528 \\
\hline Public prenatal 1st trimester & 0.442 & 0.181 & 0.383 \\
\hline Prenatal 1st trimester & 0.746 & 0.884 & 0.789 \\
\hline Maternal age & $\begin{array}{l}22.380 \\
(0.0005)\end{array}$ & $\begin{array}{l}26.798 \\
(0.007)\end{array}$ & $\begin{array}{l}22.677 \\
(0.015)\end{array}$ \\
\hline Maternal education & $\begin{array}{l}10.547 \\
(0.003)\end{array}$ & $\begin{array}{l}13.797 \\
(0.003)\end{array}$ & $\begin{array}{l}12.593 \\
(0.006)\end{array}$ \\
\hline Single & 0.501 & 0.262 & 0.682 \\
\hline Foreign born & 0.626 & 0.096 & 0.062 \\
\hline \multicolumn{4}{|l|}{ Neighborhood Characteristics } \\
\hline Share of own group with public delivery & $\begin{array}{c}0.659 \\
(0.0001)\end{array}$ & $\begin{array}{c}0.324 \\
(0.0001)\end{array}$ & $\begin{array}{c}0.613 \\
(0.0003)\end{array}$ \\
\hline $\begin{array}{l}\text { Share of own group with public prenatal } \\
\text { 1st trimester }\end{array}$ & $\begin{array}{c}0.419 \\
(0.0001)\end{array}$ & $\begin{array}{c}0.226 \\
(0.0001)\end{array}$ & $\begin{array}{c}0.425 \\
(0.0002)\end{array}$ \\
\hline Share of other group with public delivery & $\begin{array}{c}0.414 \\
(0.0001)\end{array}$ & $\begin{array}{c}0.586 \\
(0.0002)\end{array}$ & $\begin{array}{c}0.560 \\
(0.0003)\end{array}$ \\
\hline $\begin{array}{l}\text { Share of other group with public prenatal } \\
\text { 1st trimester }\end{array}$ & $\begin{array}{c}0.288 \\
(0.0001)\end{array}$ & $\begin{array}{c}0.369 \\
(0.0001)\end{array}$ & $\begin{array}{c}0.366 \\
(0.0003)\end{array}$ \\
\hline Share Asian & $\begin{array}{c}0.050 \\
(0.0001)\end{array}$ & $\begin{array}{c}0.058 \\
(0.0001)\end{array}$ & $\begin{array}{c}0.068 \\
(0.0002)\end{array}$ \\
\hline Share black & $\begin{array}{c}0.075 \\
(0.0001)\end{array}$ & $\begin{array}{c}0.070 \\
(0.0001)\end{array}$ & $\begin{array}{l}0.157 \\
(0.0003)\end{array}$ \\
\hline Share Hispanic & $\begin{array}{c}0.594 \\
(0.0002)\end{array}$ & $\begin{array}{c}0.415 \\
(0.0002)\end{array}$ & $\begin{array}{c}0.491 \\
(0.001)\end{array}$ \\
\hline Share white & $\begin{array}{c}0.248 \\
(0.0002)\end{array}$ & $\begin{array}{c}0.415 \\
(0.0002)\end{array}$ & $\begin{array}{c}0.240 \\
(0.0004)\end{array}$ \\
\hline Share of teen mothers & $\begin{array}{c}0.144 \\
(0.00003)\end{array}$ & $\begin{array}{c}0.131 \\
(0.00004)\end{array}$ & $\begin{array}{c}0.147 \\
(0.0001)\end{array}$ \\
\hline Share of single mothers & $\begin{array}{c}0.400 \\
(0.0001)\end{array}$ & $\begin{array}{c}0.342 \\
(0.0001)\end{array}$ & $\begin{array}{c}0.425 \\
(0.0002)\end{array}$ \\
\hline Share of foreign born mothers & $\begin{array}{c}0.509 \\
(0.0002)\end{array}$ & $\begin{array}{c}0.385 \\
(0.0002)\end{array}$ & $\begin{array}{c}0.471 \\
(0.0004)\end{array}$ \\
\hline Average maternal education & $\begin{array}{c}10.575 \\
(0.0001)\end{array}$ & $\begin{array}{l}11.173 \\
(0.001)\end{array}$ & $\begin{array}{l}10.753 \\
(0.002)\end{array}$ \\
\hline Average maternal age & $\begin{array}{l}26.147 \\
(0.001)\end{array}$ & $\begin{array}{l}26.491 \\
(0.001)\end{array}$ & $\begin{array}{l}26.103 \\
(0.002)\end{array}$ \\
\hline Observations & 943006 & 863890 & 152575 \\
\hline
\end{tabular}




\section{Appendix Table 3: Zipcode Level Base Regressions for First Births by Race}

(Panel 3, Table 4)

\begin{tabular}{|c|c|c|c|c|c|c|}
\hline & $\begin{array}{l}\text { Hispanic } \\
\text { Public } \\
\text { Delivery }\end{array}$ & $\begin{array}{c}\text { Hispanic } \\
\text { Public Pren. } \\
\text { First Tri }\end{array}$ & $\begin{array}{l}\text { White } \\
\text { Public } \\
\text { Delivery }\end{array}$ & $\begin{array}{l}\text { White } \\
\text { Public Pren. } \\
\text { First Tri }\end{array}$ & $\begin{array}{c}\text { Black } \\
\text { Public } \\
\text { Delivery }\end{array}$ & $\begin{array}{c}\text { Black } \\
\text { Public Pren } \\
\text { First Tri }\end{array}$ \\
\hline \multirow[t]{2}{*}{ Share of own group w/outcome } & 0.357 & 0.56 & 0.309 & 0.299 & 0.234 & 0.148 \\
\hline & {$[0.015]$} & [0.012] & {$[0.020]$} & [0.017] & {$[0.024]$} & [0.024] \\
\hline \multirow[t]{2}{*}{ Share of other group w/outcome } & 0.111 & 0.143 & 0.123 & 0.117 & 0.222 & 0.253 \\
\hline & [0.011] & [0.014] & [0.011] & [0.009] & [0.034] & [0.024] \\
\hline \multirow[t]{2}{*}{ Share black } & -0.059 & -0.014 & -0.077 & -0.015 & 0.121 & 0.241 \\
\hline & {$[0.051]$} & [0.059] & {$[0.040]$} & [0.039] & {$[0.091]$} & [0.093] \\
\hline \multirow[t]{2}{*}{ Share white } & -0.049 & 0.086 & -0.043 & -0.034 & 0.13 & 0.17 \\
\hline & [0.042] & [0.045] & {$[0.029]$} & [0.029] & {$[0.085]$} & {$[0.086]$} \\
\hline \multirow[t]{2}{*}{ Share Hispanic } & 0.016 & 0.109 & -0.066 & -0.018 & 0.06 & 0.218 \\
\hline & [0.041] & [0.041] & {$[0.028]$} & [0.029] & {$[0.077]$} & [0.083] \\
\hline \multirow[t]{2}{*}{ Share Asian } & -0.049 & -0.011 & -0.04 & -0.03 & 0.014 & 0.178 \\
\hline & [0.051] & [0.055] & [0.035] & [0.035] & [0.096] & [0.099] \\
\hline \multicolumn{7}{|l|}{ Maternal Characteristics } \\
\hline \multirow[t]{2}{*}{ Foreign born } & 0.177 & 0.097 & 0.053 & 0.034 & 0.043 & 0.011 \\
\hline & [0.002] & [0.002] & {$[0.002]$} & [0.002] & {$[0.006]$} & {$[0.006]$} \\
\hline \multirow[t]{2}{*}{ Single } & 0.164 & 0.078 & 0.231 & 0.144 & 0.17 & 0.11 \\
\hline & {$[0.001]$} & [0.001] & {$[0.002]$} & [0.002] & {$[0.004]$} & {$[0.004]$} \\
\hline \multirow[t]{2}{*}{ Teen mother } & 0.242 & 0.119 & 0.198 & 0.14 & -0.029 & -0.128 \\
\hline & {$[0.056]$} & [0.059] & {$[0.014]$} & [0.014] & {$[0.143]$} & {$[0.145]$} \\
\hline \multirow[t]{2}{*}{ Maternal age $20-29$} & 0.18 & 0.107 & 0.122 & 0.095 & -0.024 & -0.094 \\
\hline & {$[0.056]$} & [0.059] & {$[0.014]$} & {$[0.014]$} & [0.143] & {$[0.145]$} \\
\hline \multirow[t]{2}{*}{ Maternal age $30-39$} & 0.028 & -0.004 & 0.016 & 0.008 & -0.18 & -0.228 \\
\hline & {$[0.056]$} & [0.059] & {$[0.014]$} & [0.014] & [0.143] & {$[0.145]$} \\
\hline \multirow[t]{2}{*}{ Maternal age $40-45$} & -0.008 & -0.027 & -0.007 & -0.012 & -0.185 & -0.257 \\
\hline & [0.057] & [0.059] & {$[0.014]$} & {$[0.014]$} & {$[0.145]$} & {$[0.146]$} \\
\hline \multirow[t]{2}{*}{ HS drop out } & 0.271 & 0.176 & 0.26 & 0.154 & 0.252 & 0.132 \\
\hline & {$[0.002]$} & [0.002] & {$[0.002]$} & [0.002] & {$[0.005]$} & {$[0.005]$} \\
\hline \multirow[t]{2}{*}{ HS graduate } & 0.141 & 0.11 & 0.126 & 0.091 & 0.185 & 0.135 \\
\hline & [0.002] & [0.002] & {$[0.001]$} & [0.001] & [0.003] & [0.004] \\
\hline \multicolumn{7}{|l|}{ Other neighborhood characteristics } \\
\hline \multirow[t]{2}{*}{ Share teen mothers } & -0.058 & -0.054 & 0.03 & -0.021 & 0.083 & -0.018 \\
\hline & [0.041] & [0.047] & {$[0.033]$} & [0.032] & {$[0.110]$} & [0.113] \\
\hline \multirow[t]{2}{*}{ Share foreign-born mothers } & -0.097 & -0.078 & -0.068 & -0.08 & -0.146 & -0.066 \\
\hline & [0.023] & [0.024] & {$[0.018]$} & {$[0.017]$} & [0.054] & [0.059] \\
\hline \multirow[t]{2}{*}{ Mean maternal education } & 0.004 & 0.006 & 0.004 & 0 & -0.015 & 0.002 \\
\hline & [0.003] & [0.003] & {$[0.003]$} & [0.003] & {$[0.007]$} & {$[0.007]$} \\
\hline \multirow[t]{2}{*}{ Mean maternal age } & -0.005 & -0.004 & 0.002 & -0.004 & 0.001 & -0.001 \\
\hline & [0.002] & [0.002] & {$[0.002]$} & [0.001] & [0.006] & {$[0.006]$} \\
\hline \multirow[t]{2}{*}{ Share single mothers } & -0.198 & -0.131 & -0.202 & -0.127 & -0.082 & -0.078 \\
\hline & {$[0.015]$} & {$[0.018]$} & {$[0.017]$} & {$[0.016]$} & {$[0.041]$} & [0.042] \\
\hline Observations & 880305 & 861634 & 761813 & 754615 & 124553 & 122198 \\
\hline R-squared & 0.24 & 0.11 & 0.32 & 0.2 & 0.19 & 0.1 \\
\hline
\end{tabular}

Robust standard errors in brackets Includes zipcode fixed effects 